\title{
Interview
}

\section{In conversation with Michael Shepherd}

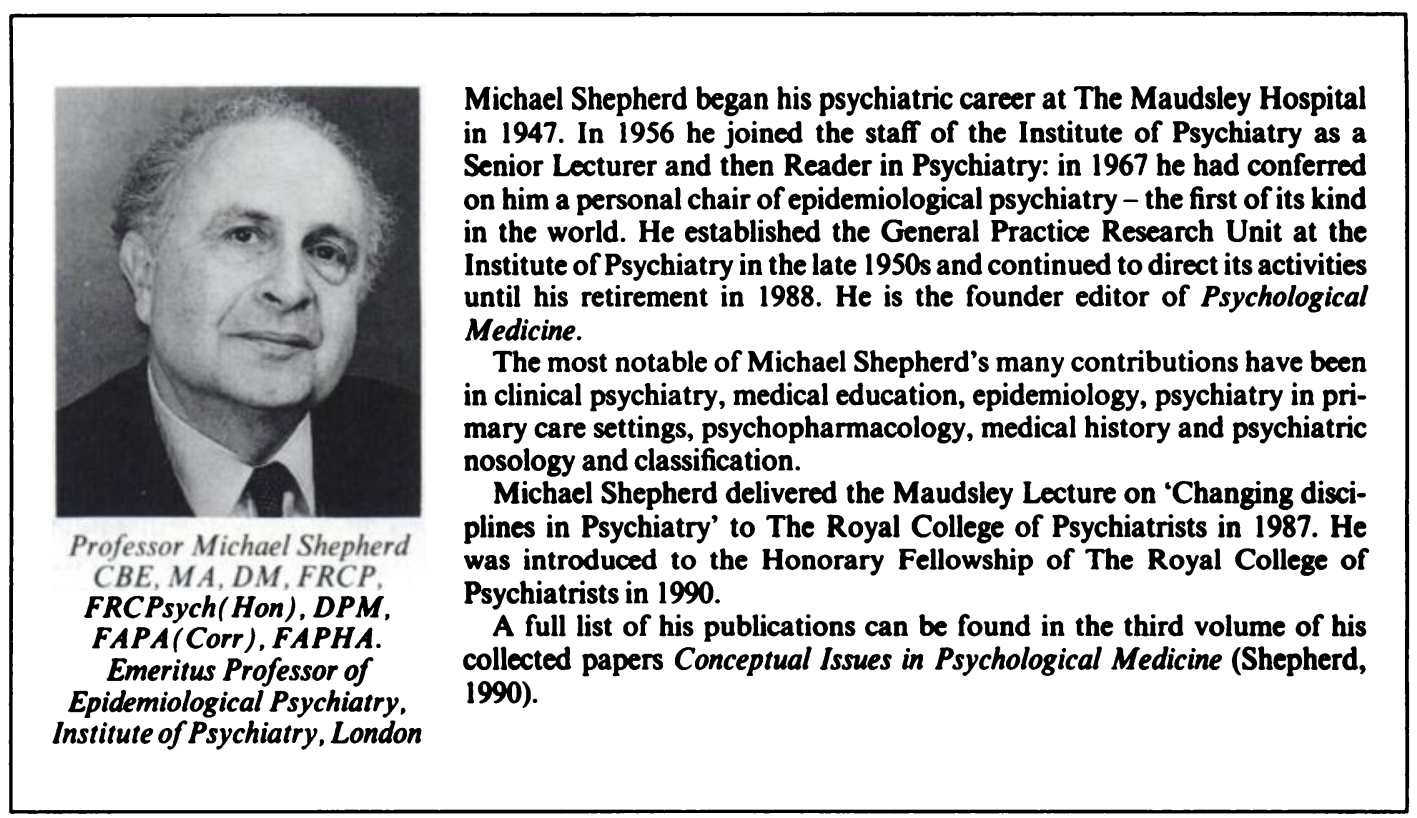

Greg Wilkinson interviewed Michael Shepherd at his home on 30 April 1991.

It has been said of you that you are Sir Aubrey Lewis's intellectual heir and this country's best-known social psychiatrist. Your name is attached to some 30 books and 150 papers and a Festschrift has been published in your honour. You also have a distinguished international reputation. Nevertheless, you are not very well known in this country. Why should this be so?

It's attributable partly, I suspect, to my own temperament and partly to the way in which my career developed. From the public standpoint the high point of my reputation was attained some years ago, when I was introduced at a meeting as the man who wrote the preface to Anthony Clare's Psychiatry in Dissent.

How would you outline the development of your professional career?

The time-honoured method is to sub-divide a professional career into four phases: 'learning', 'doing', 'directing' and 'advising', to which I would add 'reflecting' as a fifth category.

The first two phases, 'learning' and 'doing' extend roughly over the first half of my career, and fall in turn roughly into two halves. In the first period I was employed by the National Health Service, with breaks for military service and a Fellowship in the United States. During this time I underwent a thorough apprenticeship in clinical psychiatry and neurology. In the second period I joined the University staff, becoming first a senior lecturer and then a Reader in Psychiatry.

\section{Where did this take place?}

Firstly at the Maudsley Hospital and the Institute of Psychiatry. I did a long stint at Queen Square in neurology and was attached to a general hospital for a time. I spent two years in the Air Force as a specialist in neuropsychiatry, then came back to the Maudsley and worked there for another spell as a senior registrar, during which time I began to develop my interests in research.

Were the interests in research stimulated by your clinical experiences?

Very much so, often stimulated by discussion with the people with whom I was working at the time. Initially, I was learning by example, and I learnt to recognise the difference between good psychiatrists 
and not-so-good psychiatrists. Some of the senior people at the time were knowledgeable and very helpful. Apart from Aubrey Lewis there was Eric Guttmann, who was a very sound clinician, D. L. Davies, Kräupl Taylor, Erwin Stengel and Eliot Slater.

\section{What about the not-so-good psychiatrists?}

From them it was possible to learn what not to do. At that time, during the first post-war decade, practically anybody of any significance would come to the Maudsley sooner or later, either to teach or give a lecture or to provide a clinical demonstration. This provided the junior staff with a very useful bird's-eye view of what was going on and who was who.

Do you have any comments on the typology of psychiatrists?

As a group, the general psychiatrists sub-divided themselves into two broad groups. There were those who might have been general physicians or neurologists and there were those who might have been general practitioners or community doctors. The two groups were quite different in their outlook, in the way they approached the subject, in their thinking, and to some extent in their activities.

For example, if you were dealing with a ward that was full of acute psychotic patients, like the old observation ward at St Francis Hospital with which I was associated for a long time, you were very much a hospital doctor. But in a setting like that of the Air Force a medical officer was much more like a general practitioner and the sorts of problems that came up were very much more similar to those confronting a GP. Both groups, of course, contained good and bad examples.

What about psychotherapists?

They are in a class apart.

Did you play a part in teaching?

Very much so, and in a number of ways. The teaching role of senior registrars was very heavy at the time and I was involved in the running of the MPhil(Psychiatry) examination. This was not the attenuated degree it has since become, but a clinical, theoretical and research examination which enabled trainee psychiatrists to obtain a university-type education without having to take the DPM which was very much a union-ticket to a job in a mental hospital.

Who was responsible for setting up the MPhil?

Aubrey Lewis. The thinking behind it was set out in his paper, 'The Education of Psychiatrists' (Lewis, 1947). The research component of the examination was central to the procedure. Many of the people who now occupy senior positions cut their research teeth on the dissertation that they prepared for this examination.
You introduced seminar teaching at the Maudsley, which was quite novel at the time. On what model?

It was simply an adaptation of the type of tuition that I had received as an undergraduate at $O x f o r d$, where the tutorial system held sway. Lectures were not always well attended and you were encouraged to think for yourself by writing essays and engaging in tutorial discussion. The method is based ultimately on the established fact that active learning is more valuable than passive learning. Unfortunately, I gather that the system withered when the MPhil (Psychiatry) was needlessly discontinued.

Teachers as well as students can learn from this type of instruction. In my own case I recall particularly a group of seminars that I conducted on Karl Jaspers' (1923) General Psychopathology, which had not then been translated into English. I'd come across it by chance, and was so intrigued that I went through the text with the help of a German dictionary, mostly no more than a few pages ahead of the next class!

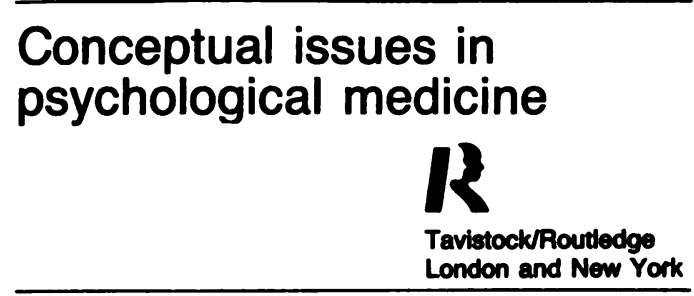

Collected Papers of Michael Shepherd

$$
\text { M. Shepherd (1990) }
$$

What type of research did you undertake at this time? At first, it was principally clinical research, writing up case-histories of particular interest. Then I settled on the large topic of morbid jealousy and I began slowly to develop interests in other aspects of research. One of them arose during my time in the Air Force when, by the merest chance, I was stationed near a mental hospital, St John's Hospital, Stone, near Aylesbury. I knew one or two people working at St John's and with the help of Dr Vera Norris, a lecturer in medical statistics at the Institute, who died tragically young, I worked out a method of using the records of this hospital to mount a large-scale investigation.

This was while you were in uniform?

Yes, the routine duties of a medical officer were not too onerous and there was plenty of time to engage in other activities! This task led me to read round the subject, and to realise that the study of mental hospital populations would qualify for epidemiological inquiry, provided that non-infectious disease was covered by the term. 
What other fields of research did you enter?

I became intrigued by the whole question of the evaluation of treatment. This was prompted by a request to look at the properties and effects of reserpine which was just coming to attention. I realised that the only way to do this scientifically would be to use the formal principles of clinical evaluation and with D. L. Davies I organised what I think was the first formal clinical trial of a psychotropic drug in this country. The climate of opinion bearing on somatic treatments was then overshadowed by the empirical spirit of Sargant and Slater's An Introduction to Physical Methods of Treatment in Psychiatry. My concern, by contrast, was with how to try and evaluate whether treatment $X$ was more effective than treatment $Y$ or a placebo. Such questions were rarely posed at that time.

You also developed an interest in follow-up studies?

Yes, I collected a large number of patients with schizophrenia and with alcoholism who could be traced by the follow-up clinic of the Maudsley Hospital. Through those studies I became interested in the natural history of mental illness which was a curiously neglected field at the time.

Carrying out such inquiries as a senior registrar I moved gradually into the academic field because this type of activity is much more suited to the academic life than it is to the work of a busy NHS senior registrar or consultant.

\section{Handbook of \\ GENERAL \\ PSYCHIATRY PSYCHO- \\ Volume 1 PATHOLOGY}

Eds. M. Shepherd and O. L Zangwill (1983)

What was the state of academic psychiatry at that time?

After the war the British Postgraduate Medical Federation was created. It contained a number of teaching hospitals which were designated as postgraduate centres within the University of London; The Maudsley Hospital was the chosen centre for postgraduate psychiatric research. This step had been recommended in 1944 by the Goodenough Committee on Medical Education which also proposed a parallel postgraduate centre in Edinburgh and the creation of undergraduate chairs in psychiatry at all medical schools.

\section{How did things turn out?}

Very little outside Denmark Hill. There were one or two small undergraduate departments and for various reasons the situation in Edinburgh did not materialise as it ought to have done. By contrast, the Institute got off to a very rapid start, but virtually without any buildings! Visitors who asked the whereabouts of the Institute of Psychiatry were told that it had no physical existence. A few huts, a few converted rooms, some laboratory space - that was all. The Institute really existed in the mind of Aubrey Lewis, whose influence was dominant. Nonetheless, if you were designated an academic worker you joined the academic staff, you were paid on a different scale, and your duties were different. And, of course, there was a much stronger obligation to undertake research than if you were a member of the NHS.

To digress for a moment: you hinted that the word epidemiology had a certain connotation in earlier times. I always thought that your work had a very strong clinical flavour to it. It was dignified by the word epidemiological. Could you comment on the difference between clinical and epidemiological as it relates to your work and the themes that you have been talking about.

The word epidemiology, from the Greek, means literally 'on the people'. Briefly, epidemiological research is essentially population research as distinct from the study of individuals which is the traditional preoccupation of clinical workers. The two approaches are, of course, complementary.

It should also be emphasised that the epidemiological method is common to investigators from a number of disciplines, including statistics, sociology, medical geography, psychology and ecology as well as clinical medicine or psychiatry. The methods are similar but the perspective will often be different.

Personally, I have always felt that if the clinical contribution to epidemiological research is to keep its end up, it is necessary to maintain contact with clinical work because many of the hypotheses that go into epidemiological research derive from clinical observation. For this reason alone I never relinquished my clinical commitments. On the other hand, you could, for example, be a biostatistician and spend a professional life-time calculating rates and numerical indices, without ever seeing a patient.

What prompted your thinking in this direction?

Much of it crystallised in the course of my year in the United States during 1955-1956. There I was attached not to a Department of Psychiatry but to the Division of Mental Hygiene within the Department of Public Health at The Johns Hopkins University, where I learnt a great deal about the theories and principles of epidemiology. It was a very stimulating experience to talk to people who were edging their way towards the same sort of things that interested me. Interestingly enough, they included very few clinical psychiatrists. Even those psychiatrists who were concerned with epidemiology undertook little, if any clinical work. 
It sounds as if you felt at home in this environment

During that time the most sympathetic groups that I encountered belonged to the Mental Health section of the American Public Health Association. This contained a diverse collection of people who were interested in public policy, economics, statistics almost everything except clinical psychiatry. This went hand in hand with my feelings of alienation from the orthodox standpoint of American psychiatry, which in the 1950 s was strongly dominated by the psychoanalytical movement, though even then there were signs of dissatisfaction.

So you felt simultaneously 'at home' and 'a complete outsider'

Yes, I tried to sum up my impressions in an article entitled 'An English View of American Psychiatry' which I wrote for the American Journal of Psychiatry. The whole situation was symbolised for me at a meeting of the American Psychiatric Association in 1956, the centenary year of Freud's birth. A centenary lecture was delivered to a huge audience by Ernest Jones who, as you might expect, gave a hagiographic account of the master and all that he represented. The very next day, at the same time and in the same place, the same audience reassembled to hear a lecture by Percival Bailey, the distinguished neurosurgeon, on 'The Great Psychiatric Revolution' which turned out to be a full-scale attack on Freud and everything he stood for. And the same people applauded Bailey just as warmly as they had Jones the day before!

\section{What did you make of it all?}

I learnt a great deal from listening to the multiplicity of viewpoints, but I was particularly impressed by the work going on in the field of psychiatric epidemiology, in which the Americans were well ahead in their activities. In particular, I became familiar with the large-scale surveys that were going on in Baltimore, New York, New Haven and Nova Scotia. At the same time there seemed to me something flawed about this approach to case definition and case detection, which was often based on self-reports or questionnaires.

It was from thinking about the possibilities of how one might improve on the method that I began to wonder about the prospects of using the primary care network in Britain as a means of case identification. This would have been impossible in the United States because the primary care system had been virtually abandoned in favour of a hospital or office-based mode of fee-for-service medical care.

In America you say they were psychiatric epidemiologists, whereas you were interested in epidemiological psychiatry. Who were the main characters involved?
Among the psychiatrists I would include Ernest Gruenberg, Alexander Leighton, Thomas Rennie, Paul Lemkau and Ben Pasamanick. There were also sociologists like Sandy Hollingshead and Leo Srole, psychologists like Joe Zubin and bio-statisticians like Morton Kramer.

What about your interest in psychopharmacology?

Because of the early studies that I had been carrying out with reserpine and then chlorpromazine, I became involved in the other great 'revolution' of the time, namely psychopharmacology. This was just starting in the United States and I met practically everybody active in that field at the time. Again, relatively few of them were psychiatrists.

\section{Who were they?}

People like Seymour Kety (neuropharmacology), Louis Lasagna (clinical pharmacology), Ralph Gerard (neurophysiology) and Joe Brady (psychology). Many workers were beginning to focus their attention on the possibilities that were opened up by the prospects of effective drugs for mental illness. And this almost meaningless word, psychopharmacology, gradually expanded and sucked in a mixed bag of people who talked a different language from that employed by the epidemiologists. As they still do.

\section{Psychiatric Illness in}

\section{General Practice}

\author{
M. Shepherd et al (1966)
}

Did you have any other formative experiences in the States?

At Hopkins my office was across the road from the splendid medical library and the Institute of Medical History. The Professor of Medical History at that time was a very distinguished scholar, Professor Owsei Temkin, who had worked with Henry Sigerist in Germany.

I used to go to the seminars and discussion groups that he organised. They confirmed my long-held belief that there was a great deal more to medical history than the standard textbooks indicated. Its relevance to psychiatry seemed to be especially relevant.

What did you do when you returned from the USA?

I entered the academic stream first as a senior lecturer, and then as a Reader. During this time there were a number of activities that I began to develop. I was now 'doing' rather than 'learning'. 
My interest in education continued and a few years later I went back to the United States for some months on a fellowship from the Association for the Study of Medical Education, to study psychiatric education in depth in the United States and compare it with the system here.

On the research front I began to build on the possibilities of using general practice as a framework for epidemiological studies. The earliest investigations began in 1957-1958 on a very small scale.

Was there anyone else working in this area at that time?

Not to my knowledge. Indeed, I was certainly not encouraged by most of the people with whom I discussed the prospects. They simply did not believe that there would be anything to find out about psychiatric illness in general practice.

What, then, induced you to investigate the matter?

First, because it seemed to me that in principle the field was worth investigating since there was a preexistent statistical framework. GPs were keeping routine records for administrative purposes and the first National Morbidity Survey had shown that one could count consultations and patterns of morbidity.

Secondly, I had put a toe in the water by approaching a local GP to request that I be allowed to sit in as a 'fly on the wall' for a number of his surgeries. I was introduced as another doctor, and listening to what was going on convinced me that there was certainly enough to merit a more systematic investigation. I had no idea, of course, of just how much morbidity we would detect, but the notion that all you would find in general practice was what was left over from the designated mental health services in hospital was clearly absurd.

Nonetheless, so widespread was this belief that the publication of our monograph, Psychiatric Illness in General Practice, in 1966 attracted little serious attention. In retrospect, it has proved instructive to ascertain why so many people should have been so biased against primary care psychiatry.

So that was one area of activity. What were the others? I initiated a large-scale epidemiological study in Buckinghamshire to do with the mental health of school children.

I also began to extend my work on therapeutic evaluation and became secretary of the newlyformed MRC Committee on Clinical Trials in Psychiatry. As a result I had the great good fortune to meet and work with Sir Austin Bradford Hill. The committee's first project was to organise a large multi-centred trial of treatments for depression. This was the first study of its sort that had been mounted and it showed that the principles of the randomised clinical trial could be applied to the treatment of mental illness, making allowances for the special difficulties, if the will and the means were available.

To what extent do you think that people have gone on to use this tool to its best effect in psychiatry?

Most clinicians must surely be aware of its existence and should be better placed to assess for themselves the value of the new drugs that continue to flood the market. Whether the average practitioner takes more notice of the findings now than he did remains an open question. Clinical psychologists have cottoned on to the method and applied it to behaviour therapy. Unfortunately it has had a rougher passage with the psychotherapists.

Your career thereafter did not follow what has now become a standard pattern

I think that was due to what politicians call events, and partly to my response to them.

Having held a Readership in psychiatry for some years, I ran into a patch of turbulence in the form of opposition to the conferment of the personal chair for which I had been nominated by the Institute of Psychiatry in the early 1960 s.

This is not the place to go into the details and eventually the matter was resolved satisfactorily. At the time, however, I was fortunate in knowing a 'mole' within the university from whom I learnt a great deal about the innards of academic politics and human sequacity. He also drew my attention to a splendid essay which helped explain much of what had been going on and which indirectly influenced my subsequent career.

\section{What essay?}

This is Francis MacDonald Cornford's (1908) Microcosmographia Academica-Being a Guide for the Young Academic Politician, a minor classic published originally in 1908 and since reprinted many times. I strongly recommend it to all aspiring academics.

\section{Can you indicate its content?}

Cornford was a Greek scholar who begins his booklet with a quotation from Plato's The Republic.

"Any one of us might say that although in words he is not able to meet you at each step of the argument, he sees as a fact that academic persons, when they carry on study, not only in youth as a part of education, but as the pursuit of their maturer years, most of them become decidedly queer, not to say rotten."

On this premise the argument is essentially a polemic against the corrupting influence of academia and its environment. The style, however, is as important as the content. The best of the television 'Yes, Minister' series catches the tone in a more genial key.

\section{Can you give me an example?}

Cornford points out that academic politicians are not so much dishonest as fearful, displaying what he 
refers to as "genuine, perpetual, heartfelt, timorousness". He continues by pointing out that the most important branch of academic politics is connected with Jobs - he always spells jobs with a capital $\mathbf{J}$ which, he says, fall into two classes, My Jobs and Your Jobs:

"My Jobs are public spirited proposals, which happen (much to my regret) to involve the advancement of a personal friend, or (still more to my regret) of myself. Your Jobs are insidious intrigues for the advancement of yourself and your friends, speciously disguised as public spirited proposals."

This may convey a touch of the essay's spirit. But what also impressed me at the time was Cornford's conclusion. While assuming throughout that his argument will be rejected by the would-be ambitious academic politician, his final paragraph reads as follows:

"If you find that I was right, remember that other world, within the microcosm, the silent, reasonable world where the only action is thought, and thought is free from fear.

If you go back to it now, keeping just enough bitterness to put a pleasant edge on your conversation, and just enough worldly wisdom to save other people's toes, you will find yourself in the best of all company - the company of keen humorous intellect; and if you have a spark of imagination and try very hard to remember what it was like to be young, there is no reason why your brains should ever get woolly or why anyone should wish you out of the way."

Those words express very well the sentiments that I was forming at the time and which helped make me decide to concentrate the second half of my career on directing and advising in the spheres of clinical work, teaching and research rather than in those of medical politics and administration.

Would you say, then, that you opted for the ivory tower?

If you want to call it an ivory tower you can, but I assure you that the ivory comes from just as many wild elephants inside the tower as there are outside. The advantage resides more in the increased possibility of spending at least some time in Cornford's 'silent, reasonable world'.

Let us move on to the second half of your career First of all came the setting up of the General Practice Research Unit. This took some doing because it was not a very popular subject at the time and I had to obtain money from various sources until the Department of Health assumed financial responsibility. The Unit continued until my retirement in 1988 . Some 30 books and 400 papers attest to its productivity. I think that it has helped to establish primary care psychiatry as a major area of research and practice.

Has primary care psychiatry become as successful internationally as it has in this country?
That is very difficult to assess. The subject is now recognised as a top priority by WHO. It appeals to many individual workers, in many other countries but they are often handicapped by the fact that their system of medical care does not lend itself to this type of investigation. In this country it has been creeping into the system rather than coming in with a bang and it has had to overcome opposition from both hospital psychiatrists and general practitioners for quite different reasons.

What about the relationship between research and policy?

This question raises a general issue. If you engage in epidemiological research, the very nature of the work tends to carry policy implications, unless it is of a purely abstract nature like, say, a new statistical technique. There is an understandable temptation therefore for workers in the epidemiological field to want to become decision makers and try to implement and promote their own findings. This tendency introduces bias and can vitiate the value of much so-called health-services research. The history of 'deinstitutionalisation' illustrates the theme only too well.

All the early studies that we carried out were focused entirely on the nature and amount of psychiatric illness in the community identified via the GP. I never regarded the practical implications of the data as our primary concern, though as the subject attracted increasing attention during the 1980 s we became much more involved in such considerations.

The Unit also provided a training ground for rather a lot of doctors, many of whom achieved professorial status. How do you account for this?

Although the Unit was never numerically very large I was always of the opinion that one of its principal objectives was to train its members in research methods with an academic career in mind. Not all alumni took this direction: they include a researchdirector in a pharmaceutical company, a private practitioner and even a psychoanalyst.

The Unit was always multidisciplinary and we also helped train workers in non-medical fields statistics, sociology, social work, psychology. I should like to have included more GPs on the staff, but the career-structure of general practice made this difficult to achieve.

What about other activities during this phase of your career?

There were several topics of research which may be covered briefly. I maintained close contact with St John's Hospital throughout this period and have collaborated with the former medical director, Dr David Watt, on a number of projects. The most recent has been a large-scale study of the natural history of schizophrenia. 
The MRC Committee for Clinical Trials in Psychiatry, of which I became chairman, initiated the prosecution of a number of studies which were carried out over a period of about 20 years.

Then there was the setting up of a psychopharmacology research unit with Professor Heinz Schild, who was Professor of Pharmacology at University College. This was, I think, the first of its kind and included Hannah Steinberg, a psychologist who became the first professor of psychopharmacology in this country, J. D. Montague and Malcolm Lader. Much of this work was multidisciplinary and stimulated me to write Clinical Psychopharmacology with Professors Lader and Rodnight (1968); this turned out to be the first textbook on the subject.

I might also mention the MRC-funded project on noise as an environmental pollutant. This had to do originally with the adverse effects of aircraft noise on mental health, but was extended to incorporate experimental work.

At the same time I was involved with the US-UK project, which I helped to direct for a while.

In addition, I was invited to take some responsibility for various WHO programmes, particularly those connected with the International Classification of Diseases. I think it is fair to say that this work played a large part in reviving the international community's concern for psychiatric diagnosis and nosology. When the programme commenced in the middle 1960 s, no more than three or four member countries of WHO out of more than 130 were using the ICD. By means of a two-pronged approach based on diagnostic exercises and education, we generated a great deal of interest in the field.

Do you think that -thinking of the United States in particular-it is possible to say that certain elements might have gone too far in an apparent obsession with diagnosis and classification?

In the United States there has been something of a conversion phenomenon. In the 1960 s it proved difficult to persuade the Americans to participate in the WHO programme. They had virtually abandoned the notion of diagnosis in favour of the 'dynamic' formulation. Now what they call neo-Kraepelinian psychiatry is all the rage, with DSM as its foundation. This is probably better than the earlier diagnostic nihilism, but it becomes stultifying when so many of the categories are both logically and clinically suspect.

Returning to your activities, what of 'Psychological Medicine'?

I have tried to indicate elsewhere why and how this journal was set up. It has sometimes been compared mistakenly to the British Journal of Psychiatry but they have very little in common. The British Journal of Psychiatry is an association journal, an official publication of the College which comes to Members and Fellows automatically. Psychological Medicine is an independent journal, international in scope, dependent on subscriptions and concerned primarily with research in psychiatry and cognate disciplines. After 20 years it remains a quarterly, but it has greatly expanded to more than 270 pages an issue and carries a variety of special features, for example, commissioned editorials, research reports, and monograph supplements.

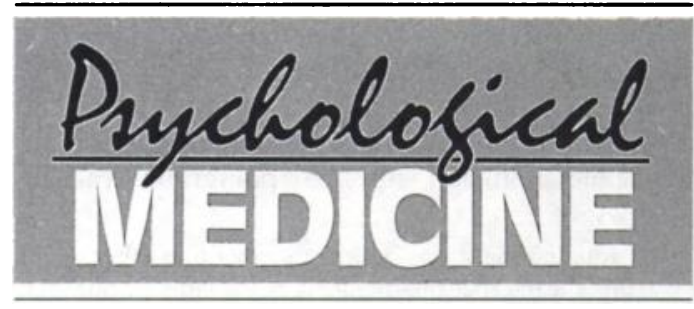

Our original aim was to further the continuing education of professors of psychiatry, but it was soon pointed out that in too many instances they are rendered ineducable by a carapace of omniscience. We therefore aimed at creating a journal which would contain the best work available and help set standards and create incentives, especially for younger workers. One of the hallmarks of any wellestablished professional group is the existence of flagship journals that represent the group's aspirations and achievements. How far I have succeeded is difficult to judge: it is hardly possible for an editor to assess the quality of his own journal since he has no way of knowing who reads it or how it is regarded. Perhaps the most judicious comment was made by the editor of the Archives of General Psychiatry who remarked that Psychological Medicine led the field in respect of "intellectual fortitude".

Is it true that you have written many of the short, anonymous book reviews yourself?

Unfortunately, yes. Not out of choice, but because of the difficulty in persuading colleagues to undertake the task and to do it quickly. In my view a journal with the objectives of Psychological Medicine must have a comprehensive book-review section.

There were other activities concerned with editing and writing?

Indeed there were. Perhaps I might here refer to translation which seems to me to be an area of particular importance. I am a believer in having the original text in other languages, and have always tried to have as much of my own work, and that of my colleagues, translated into as many other languages as can be arranged. Although English is the scientific lingua franca, workers in other countries do not always read it easily and it helps greatly if the 
material can be read in a serviceable translation. For the same reason I took some trouble to oversee the publication of two books of translated foreign papers, mostly French and German, into English.

In recent years I have probably written and edited more material than at any other time. Some of this work consists in the writing up of research, some of it represents more general interests. Among these I would include the five volume Handbook of Psychiatry, the Scientific Basis of Psychiatry series, the volumes entitled Psychiatrists on Psychiatry and Non-Specific Aspects of Treatment and my jeu d'esprit on Sherlock Holmes and Sigmund Freud. The fruits of 'reflecting'!

\section{Sherlock Holmes and the case of Dr Freud \\ M. Shepherd (1985)}

Did you have time to enter into formal involvements with committees and professional bodies?

Certainly. Apart from sitting on the usual committees I was actively involved in advising on the mental health initiative taken by The Wellcome Trust. This has proved particularly important as money for research has dried up elsewhere. There was a spell on the Noise Advisory Council and the Council of the Section of Psychiatry of the Royal Society of Medicine, of which I was elected president. I have ongoing commitments to WHO and the EEC. And, of course, one is constantly involved in unofficial activities of an advisory nature, but I do not think there is much point in mentioning these. They come naturally as part of the job.

Another special interest that you have hardly mentioned so far and on which you have been publishing more recently concerns historical themes in psychiatry.

During the last 20 years professional historians have taken an expanding interest in the history of psychiatry. Several social historians have made a career out of the study of the social aspects of psychiatry. Many of them are gifted historians who know a great deal about the subject but they tend to be ignorant about mental illness itself. I have long felt that there is a place for a contribution to be made by medically qualified scholars who are familiar with the historical method and outlook.

I did this myself once on a small scale by working with a very eminent historian. It was an arduous but rewarding experience which taught me that it is necessary to place your medical material in its historical and social context and view it in relation to a whole host of non-medical factors.
Further, medical history can be of more than scholarly interest, especially in the less well-developed branches of medicine. If, for example, you take a topic like infectious diseases, which has moved from the pre-scientific into the scientific area with the coming of bacteriology, the miasma theory of disease is of largely academic interest. However, when dealing with a barely scientific discipline like psychiatry historical studies can be directly relevant to on-going issues.

\section{Can you give an example?}

A good example is provided by the current debate on the so-called recency hypothesis: did schizophrenia exist before the 18th century? This question has already attracted a great deal of interest among both historians and psychiatrists. It is not a purely academic topic in the sense of the miasma theory for it bears on the current discussion concerning the viral theory of schizophrenia. Psychiatrists in training would benefit from knowing more about the history of their subject. They would find that the broader aspects of the discipline can only be understood in their historical context. Many of these are illustrated in the three volumes of The Anatomy of Madness that I put together with Drs Bynum and Porter, both of them medical historians. Incidentally every issue of Psychological Medicine to date carries an historical article to help give the subject a boost.

Would psychoanalysis benefit from historical analysis? Psychoanalysis is almost incomprehensible if it is not viewed in the context of the history of ideas. That is why some of the philosophical critiques are so cogent. Popper refuted its scientific pretensions outright. Wittgenstein (1989) called it a 'powerful mythology' and remarked that "this whole way of thinking wants combatting". Gellner (1985) refers to psychoanalysis as a "complex belief system satisfying social needs in a scientistic idiom" and emphasises the need to appreciate that it is not only a doctrine but also an institution, a technique, an organisation, an ethic, a theory of knowledge, an idiom, a climate of opinion, a theory of culture, aesthetics and religion. An historical perspective is indispensable for an analysis (if I may use the word) along these lines.

You have criticised psychotherapy and psychoanalysis for other reasons.

I would not identify psychoanalysis with psychotherapy. What we now call psychotherapy, however it be defined has been and remains part of the physician's placebological role as healer. In his authoritative monograph on psychotherapeutics, Psychological Healing, Pierre Janet (1919) traces the evolution of the root activity from magical and religious practices to its various contemporary branches, of which psychoanalysis is one. Janet calls it a form of 'mental liquidation' and comments on its 
deficiencies from the standpoint of a psychopathologist. Over and above such considerations there is also the question of the place of psychoanalysis in medicine. Here I would refer to the situation in the United States where after World War II the subject was given its head in an unprecedented manner in most academic departments of psychiatry. Since then it has failed signally to live up to the expectations that were roused and its reputation has declined sharply. This is partly the reason for the swing towards biological psychiatry today. Whatever the future may hold for the psychoanalytical movement it will, I think, move increasingly away from medicine.

\section{THE SCOPE OF EPIDEMIOLOGICAL PSYCHIATRY}

\author{
Essays in Honour of \\ Michael Shepherd
}

Eds. P. Williams, G. Wilkinson and K. Rawnsley (1989)

Another question, indirectly related to this theme, stems from a remark you made at a symposium on the history of psychopharmacology - "the dark before the dawn". Drawing on your own observations made 30 years previously you conclude "That was how the biological dawn appeared to one observer who is still waiting for the skies to lighten". Would you expand on this?

My contribution to that symposium was focused on one category of drugs, the so-called neuroleptics and their place in the management of schizophrenic illnesses. On the basis of my own experience I tried to indicate how far and why the situation was removed from the standard account of the matter. In a sense it represents a continuation of my interest in the evaluation of treatment, here viewed retrospectively in the light of the many factors that bear on the introduction, promotion and reputation of a treatment in psychiatry. An example of oral history.

\section{Do you have a last word on lithium?}

The lithium episode illustrates another aspect of the comment that I have just made. It arose as a result of the paper that I published with Dr Blackwell in 1968 just at the time when, unknown to us, the lithium bandwagon was about to roll. All we did was to discuss some of the flaws in a study published by the Danish workers, Baastrup and Schou, in the previous year, purporting to demonstrate that lithium could effectively prevent manic-depressive disease. We felt that the claims were premature and that more rigorous methods of evaluation should be applied. The heat generated by this controversy was in large measure artificial and served largely to publicise the topic. After 20 years the last word might go most appropriately to one of the Danish workers, Dr Baastrup (1988), taken from his paper on the subject delivered in 1987 at the 2nd British Lithium Congress:

"In 1967 Professor Schou and I published a joint paper entitled 'Lithium as a prophylactic agent'. We both considered the title a good one - what we intended to demonstrate was that continuous lithium treatment made it possible to change the course of a manic-depressive illness in such a way that the patient no longer experienced psychotic episodes. The use of that title was a grave mistake! And - having been brought up in a country where modesty is considered the prime virtue, we ought to have known better. We have been pretentious enough to claim that we could present a method for the prevention of mental illness."

This interview is to appear in an issue of the 'Psychiatric Bulletin' celebrating 150 years of professional psychiatry in Britain and perhaps we should conclude by saying something about The Royal College of Psychiatrists. Is it true that you have not involved yourself a great deal in College affairs?

To say that I have not been asked would be a more accurate comment. I was quite actively engaged in the work of The Royal Medico-Psychological Association and was on a number of committees. Since the formation of the College, however, I have been more a well-wishing bystander than a participant. Many of my colleagues, I would add, have been in the same position.

Have you formed an opinion on how the College has developed over the past 20 years?

In many ways its development reflects its origins. Dr Howells (1990) gave a very clear account of the tortuous way in which the College came into being and of the internal opposition to its formation. The extent of that opposition is manifest in the contributions of influential figures like Denis Hill, William Sargant and Alexander Walk, to the debate on 'The Future of Organised Psychiatry in Great Britain and Ireland' held at the quarterly meeting of the RMPA in November 1963 and published as a special supplement of the British Journal of Psychiatry (1964). The people who were pushing for the College were principally the mental hospital doctors who felt they would receive the short end of the stick under the aegis of The Royal College of Physicians. Numerically, of course, they constituted a substantial majority and when, rather unexpectedly, the College came into being many of the original opponents of 
the College made U-turns in order not to be left out of the action. Nonetheless, the two factions made uneasy bedfellows.

Since then a curious situation has arisen. On the one hand, as in other branches of medicine, the creation of a Royal College is clearly important. Many observers have remarked that this country is basically run by clubs, and Royal Colleges are special forms of clubs which have their own interests. In this case the College grew out of the RMPA which was essentially a club for mental hospital superintendents representing institutional psychiatry. Since 1970, however, the institutional base of psychiatry has been eroded by the run-down of the mental hospitals. The bulk of the psychiatric profession still retains links with the crumbling structure of the hospital organisation, but the pressure to develop some form of community psychiatry is driving them into uncharted waters. The resulting dilemmas were well summarised in a Lancet (1985) editorial entitled 'Psychiatry - a discipline that has lost its way', and when Professor Rawnsley (1984) devoted his presidential address to the theme of 'Psychiatry in Jeopardy', he drew attention to those difficulties from the somewhat inward-looking vantage-point of the College.

As a consequence of this trend it has become evident that whereas formerly the psychiatrists were undisputed masters in their own asylums, they now find representatives of several other disciplines snapping at their heels. I outlined this interprofessional rivalry in a paper 'Who should treat mental disorders?' that was based on material prepared for the College's Cambridge conference on psychiatric education in the early 1980s. It is evident that the general physician, the general practitioner, the clinical psychologist, the social worker, and the nurse, all lay claim to manage various forms of mental disorder and do not take the expertise of the psychiatrist for granted. The Lancet (1985) editorial (for which I was in no way responsible) puts the matter bluntly:

\footnotetext{
"Much of the progress made by psychiatry in the past generation has taken place because psychiatrists themselves have led the way. It is sad that ... their place as pioneers has been usurped by planners and politicians. It is time for the speciality to emerge from its torpor, cease its self-flagellation, and take on the mantle of leadership again."
}

Here, I suggest, is both a challenge and an opportunity for the College. To meet the one and take up the other will call on all its resources, scientific as well as political. Many of us hoped for a strong research and academic dimension when the College was set up. This, I gather, is slowly evolving and should prove invaluable in the years ahead.

I should like to congratulate the College on this 150th Anniversary and extend my best wishes for its future well-being.

\section{References}

BAastruP, P. C. (1988) Lithium reflections II. In: Lithium: Inorganic Pharmacology and Psychiatric Use (ed. N. J. Birch). Oxford: IRL Press. Pp. 5-7.

British Journal of Psychiatry (1964) The Future of Organised Psychiatry in Great Britain and Ireland. British Journal of Psychiatry (special supplement, May).

CORNFORD, F. M. (1908) Microcosmographia AcademicaBeing a Guide for the Young Academic Politician (11th impression, 1983). London: Bowes \& Bowes.

Gellner, E. (1985) The Psychoanalytic Movement or the Coming of Unreason. London: Paladin.

HowelLs, J. (1990) In conversation with John Howells (interview by $\mathrm{H}$. Freeman). Part 1: Psychiatric Bulletin, 14, 513-521. Part 2: Psychiatric Bulletin, 14, 577-581.

JANET, P. (1919) Les Médications Psychologiques. 3 Volumes. Paris: Alcan.

JASPERS, K. (1923) Allgemeine Psychopathologie. Springer Verlag: Berlin. English translation from the German by J. Hoenig \& M. W. Hamilton (1963) General Psychopathology. Manchester: Manchester University Press.

The Lancet (1985) Psychiatry - a discipline that has lost its way. The Lancet, $i, 731-732$.

LEWIS, A. (1947) The education of psychiatrists. The Lancet, ii, 79-83.

RAWNSLEY, K. (1984) Psychiatry in jeopardy. British Journal of Psychiatry, 145, 573-578.

ShePHERD, M., LADER, M. \& RODNIGHT, R. (1968) Clinical Psychopharmacology. London: The English Universities Press.

\& ZANGWILl, O. L. (eds) (1983) Handbook of Psychiatry. Vol. 1. General Psychopathology. Cambridge: Cambridge University Press.

-, CoOper, B., Brown, A. C. \& Kalton, G. (1966) Psychiatric Illness in General Practice. Oxford: Oxford University Press.

(1985) Sherlock Holmes and the Case of Dr Freud. London and New York: Tavistock Publications.

- (1990) Conceptual Issues in Psychological Medicine. London: Routledge.

Williams, P., Wilkinson, G. \& Rawnsley, K. (1989) The Scope of Epidemiological Psychiatry: Essays in Honour of Michael Shepherd. London and New York: Routledge.

Wittgenstein, L. (1989) Conversations on Freud. In: Sigmund Freud: Assessments (ed. L. Spurling). Volume 4. London: Routledge. Pp. 252-253. 